\title{
The Structure and Psychometric Properties of Wellness for A Sample of Teachers in Egypt
}

\author{
Mokhtar Ahmad Al-Kayal, Ph.D. ${ }^{1} \quad$ Mohammad Ismail Sayed Hemeda, Ph.D. ${ }^{1}$ \\ Mohammad Ali Haeba, Ph.D. ${ }^{1}$ Walid Hassan Ashour El Khateeb, Ph.D. ${ }^{2}$ \\ 1. Educational Psychology Department, Faculty of Education, Ain Sham University. \\ 2. Educational Psychology Department, Faculty of Education, Ain Sham University and Jouf University.
}

\begin{abstract}
The present study attempts to examine the structure of wellness for a sample of teachers in Egypt and examine psychometric properties of wellness Inventory. The study questions addressed are: is the structure of wellness multidimensional or uni-dimensional?, Is wellness inventory has appropriate psychometric properties?. A total of 417 teachers from Egypt completed the inventory of wellness, including males $(\mathrm{N}=260)$ and females $(\mathrm{N}=$ 157). The teachers ranged in age from 29 to 48 with an average age 36.7 and S.D. 1.7 . The inventory that used in this study is referred to as the multidimensional organizational wellness inventory (MOWI) (Fasone, 2017), Confirmatory factor analysis (CFA) is used. The results indicates that The structure of wellness is multidimensional which includes physical, emotional, social, intellectual, spiritual, occupational, and environmental. And the inventory has appropriate psychometric properties.
\end{abstract}

Keywords: Wellness, Reliability, Construct Validity

DOI: $10.7176 /$ RHSS/9-16-04

Publication date: August $31^{\text {st }} 2019$

\section{Introduction}

Wellness is considered to be an important indicator of future health and lifestyle habits and an endpoint of many physical mental or social interventions (Rachele, Washington, Cuddihy, Barwais, \& Mc Phail, 2013,p. 162). Roscoe (2009, p.219) pointed out that wellness is basic concept for flourishing the current approach of positive psychology. It plays an important role in counseling and development as well as developing huge number of theories, models, and measures of wellness.

Wellness is unitary concept which includes balance and integration between various components to achieve high levels of optimal functioning. It isn't a goal in itself, but it is a continuum process which leads to development (Jankowski - Koch, 2014, p.4). Rachele, Cuddihy, Washington, \& Mc Phail (2014,p.1) asserted that wellness is considered to be an important construct which presents and offers a point of difference to other health-related concepts.

Wellness is an important concept for mental health and appropriate field for research and active practice specially in psychological counseling. Theorists conceptualized wellness as a combination from various variables which predict with holistic well-being, others asserted that wellness is an unidimensional concept (Harari, Waehler, \& Rogers, 2005, p.94).

Bates, Cooper, \& Wachs (2001, p. 193) stated that wellness is an important to attempt to assist individual to develop health lifestyle which in turn promotes high levels of self-esteem. Gradid \& De Jager (2011,p.517) proposed wellness as an appropriate model for guidness, counseling and professional development which aims to promote optimistic human behavior.

Wellness includes life and better performance, It means not only absence of illness, but it represents existence of positive characteristics such as positive emotion, positive social interact and positive functioning, It interferences with other concepts such as positive mental health, well-being and happiness. It is a multifaceted concept which integrates well-being with ability for good behavior (Schueller, 2009, p.329)

In recent years, the issue of promotion wellness occupied the researchers' attention in counseling field and human development. It linked with many populations and professions such as children, patients, teachers and patients with physical and mental disease (Day-Vines, 2007, p.82). Ragheb (1993, p.22) pointed out that we need to measure wellness, valid and reliable, to assist practitioners and scientists.

Since wellness related to professional development, Its importance became clear specially in teaching field, teachers need to feel with holistic wellness which in turn is reflect positively in their career and is resulted in their students' academic achievement.

1.2. What is wellness?

The history of wellness began 1961 by Halbert Dunn who termed the concept of wellness and defined it as a method for behavior which is guided to maximizing individual's ability. Later, many theorists presented number of theoretical frameworks for wellness. They agreed that wellness is lifestyle through which one takes active role 
in defining the level of wellness (Palombi, 1992.p.221).

Wellness is multifaceted state which describes one's health state focusing on wellbeing and quality of life. It can be said it reflects positive dimensions for holistic approach including the conditions related to subjective and emotional sides (Fridlund, Martensson, Baigi, \& Brostorm, 2015, p.366). It reflects the process of promotion quality of life through integration and balance of spiritual wellness, mental wellness and physical wellness for one (Harari et al., 2005, p. 93).

Hurtado - Pardos, Casas, Lluch- Canut, Moreno - Arroyo, Nebot-Bergua, \& Roldan - Merino (2006,p.1) defined wellness as optimal state for health of individuals and societies. Bates et al. (2001, p.193) see wellness as active process through which one becomes more aware and ability to make choices towards clear healthy existence. Roig (2017, p.3) defined wellness as conscious process that one should aware of it to achieve better lifestyle that is directed to optimal health and well - being. This mean that body, mind and soul integrate together in individual and resulted in his behavior and lifestyle. Wolf, Thompson, \& Smith - Adcock (2012, p.164) defined wellness as the quality and state and an indicator to one's good health especially as a goal one seeks out to achieve in active manner.

Wellness refers to state of positive well - being and optimal health through engagement in positive healthy behavior, the indicators of positive health include personal and professional development and the ability to engage holistically in life (Al Hadid, Becker, Mansour, Al- Shubi, Tharwat, \& Glascoff, 2013, p. 230).

Rachele et al. (2014,p.1) perceived wellness as multidimensional holistic notion focusing on human life to live better life in optimal health. (Fridlund et al., 2015p. 366) pointed out that wellness is described more than absence of negative elements such as illness, It includes positive elements such health and happiness. It shapes one's role through his behavioral response and his attitudes towards his society, family members, friends and peers. This mean that the effect of these relations on wellness depends on one's need and demands as well as support resources which one received from others and social support to maintain or restore wellness.

Roscoe (2009,p.216) pointed out that although there is a great interest in literature of wellness, there is little consensus about the definition of this concept.

The current study defines wellness as optimal state of health through balancing and integrating physical, emotional, social, intellectual, spiritual, occupational and environmental wellness which lead to quality of life, life satisfaction, happiness, wellbeing, professional development and the ability to engage holistically in life skills. It shapes one's positive behavioral responses and his attitudes towards his society and others.

1.3. Structures and dimensions of wellness

Wellness model has gained popularity as positive, integrative and holistic approach depends on promotion to understand human behavior (Myers, Luecht, \& Sweeney, 2004, p.194).

The holistic model of wellness is considered to be one of important models of wellness. So, there are many various definitions and approaches for this model. This model is derived from the theoretical structures and the empirical studies in many fields including psychology, anthropology, sociology, religion and education (Vafaeenia, 2014, p.24-40).

Holistic model of wellness is approach depends on the strengthen mental health, development and counseling. It is very important in improving personal responsibility, self-care to achieve daily better choices, It links health related to physical activities and nutritional awareness, stress management, spirituality, and environmental sensibility (Vafaeenia, 2014, p.24-40).

Theorists believe now that wellness includes a holistic view for one which includes intellectual, emotional, and spiritual wellness. and wellness is consisted of six discriminated unrelated components: physical, intellectual, social, spiritual, occupational, and emotional wellness. While current models of wellness proposed that wellness includes only five dimensions: spiritual, social, intellectual, emotional and physical. Other models suggest that wellness includes seven dimensions: spiritual, intellectual, occupational, environmental, social, physical and emotional wellness (Lowe, 2015, p.37).

Bucker (2016,p.7) pointed out that wellness consists of social, occupational, intellectual, spiritual ,emotional ,physical health which promote health in general and are considered to be from the important means to achieve wellness. And although there are many various models and conceptualizations about wellness, yet few studies examined it empirically. Adams et al.(2000,p.165) stated that the little is still known about wellness and few studies addressed identifying dimensions of wellness (Beauchemin, 2015,p.2-3).

Young, Turnage - Butterbaugh, Degges - White, \& Mossing (2015,p.222) asserted that we need to examine wellness, Tatar(2010,p.18) pointed out that the literature which deals with holistic models of wellness is still few, yet the results of many studies revealed that the physical factor as well as various physical factors influence on wellness.

1.4 .Measuring of wellness

Since the concept of wellness appeared, the main issue that faced theorists of wellness is how to measure it 
accurately. This issue was addressed through developing tools and instruments that measure the behavioral components of wellness. Much measurements of wellness assist individual as a tool to achieve wellness lifestyle (Palombi, 1992, p.221).

Rachele et al. (2014, p.1-2) pointed out that wellness instruments drived from many theories which assist researchers, scientists and practitioners to apply this concept in many contexts and settings. He pointed that wellness instruments may be used as educative self-assessment tools to identify at - risk elements of an individual's life as a tool to facilitate the counseling process.

Rachele et al. (2013, p.163-165) stated that wellness evaluation assist in applying and evaluating interventions and programs related to wellness for adolescents which aims to promote positive lifestyle behavior. The effectiveness measures of wellness have many important implications in many fields including health care, education, and counseling.

Hattie, Myers, \& Sweeney (2004, p. 355-363) concluded that we still need to measure validity and reliability for many measurements which related to healthy behavior generally and the behavior that promote health specially wellness. Wellness is observed and measurable behavior and developing such measurements is available and possible. They pointed out that we need additional and future studies in wellness to identify the structure and factors of wellness.

Myers et al. (2004,p.194-206) asserted that the current measurement of wellness needs clear conceptualized and theoretical models defining the structure of wellness based on empirical studies, We need additional studies to identify and offer new measurements for wellness.

Many studies addressed the psychometric properties of wellness across different populations and samples, Palombi (1992) investigated the psychometric properties of three wellness measures and addressing the issue of construct validity of wellness. These measures are wellness inventory, life assessment, questionnaire and the lifestyle coping inventory. These measures were demonstrated to be internally consistent and reliable instruments. A coefficient alpha of 0.93 was obtained for all three of the instruments. A coefficient alpha of 0.93 was obtained for all three of the instruments' total scales.

Bates et al. (2001) addressed a validation of two subscales for the salubrious lifestyle scale and lifestyle assessment. The sample contained of 203 undergraduate participants (67 males and 136 females: mean age $20.22, \mathrm{SD}=1.71$ ) from two southeastern universities. The study found positive correlation between the proposed subscale and the two established subscales demonstrated concurrent validity.

Hattie et al. (2004) studied the psychometric properties of wellness. The sample consisted of 3.043 persons including 10 to 18 years old $(\mathrm{N}=213)$, university students $(\mathrm{N}=1.357)$, young adults $(20-35$ years, $\mathrm{N}=524)$, middle- aged adults (36-55 years, $\mathrm{N}=662)$ and older age adults $(56+$ years, $\mathrm{N}=184)$. The study used the 103- item WEL. The exploratory and confirmatory factor analysis of the items revealed five primary factors of well-being (creative, coping, social, essential, and physical) and 1 super ordinate factor identified as "wellness".

Becker, Whetstone, Glascoff, \& Moore (2008) examined test the psychometric properties of the adult version of the multidimensional salutogenic wellness promotion scale (SWPS), a tool designed to measure positive health. The sample of 304 administrative, academics, and staff personal tested the psychometric properties of the adult version of the SWPS. The resulted revealed that the SWPS demonstrated it had a seven factor multidimensional structure, had good internal consistency, and was positively correlated with structure, had good internal consistency, and was positively correlated with perceived health at 0.001 level and life satisfaction at 0.001 level. Validity was also supported by negative correlations between the SWPS and both a depression and symptom measure. The SWPS demonstrated good evidence of reliability and validity.

Becker, Moore, Whetstone, Glascoff, Chaney, Felts, \& Anderson (2009) conducted a study to test validity, reliability, and uses of the multidimensional salutogenic wellness promotion scale (SWPS). The sample included 2140 participants from a large university. Results of EFA suggested the existence of seven factors that were consistent with the theoretical factor structure that was assumed a priori and was consistent with the structure originally found in studies using this scale. The analysis of frequency distribution, means, correlations, and regressions found significant relationships between measured health behaviors, perceived health and GPA. The SWPS provides valid and reliable information about positive health potential for research and field health professionals.

Gradidge \& De Jager (2011) addressed psychometric properties of the wellness questionnaire for higher education. The sample consisted of 1.726 higher education students of national origin in South Africa. Factor analysis was carried out and revealed seven factors (physical, career, intellectual, environmental, social, emotional, spiritual wellness). The reliability coefficients of the scale are regarded as satisfactory since all were found to be greater than 0.70 .

Rachele et al. (2014) investigated study aimed to evaluate the test-retest (intra-rater) reliability of the 5FWel instrument. The sample consisted of 46 participants (from adolescent females) aged between 12 and 14 years from secondary school with catholic affiliation in a metropolitan area of Brisbane, Australia. The study used the 5F-Wel T version is a 97 item questionnaire which includes attitudinal and behavioral statements. The 
results revealed that the total wellness scores remained comparatively stable between assessments.

Fridlund et al. (2015) conducted a study to replicate and establish the psychometric properties of 74 - item comprehensive Ethos towards wellness questionnaire in healthy Norwegian population in light of content and construct validity as well as homogeneity and stability reliability. The study used sample consisted of 214 healthy middle-aged participants. It used questionnaire consisted of $74-$ item. The results revealed that the construct validity of questionnaire involves four factors (work life, family life, spare time, ethos brief). Reliability in terms of homogeneity (Cronbach's7.70) and stability (intraclass correlation coefficient $>0.70$ ).

Hurtado - Pardos et al. (2016) examined validity of an instrument to measure the wellness among university nursing faculty. It was performed in two phases. Phase 1 consisted of the development the instrument with discussion groups and participants consensus. The instrument included 12 items or psychosocial risk factors. The items were grouped into three dimensions: teaching work demands, curricular demands, and organizational difficulties. Phase 2 evaluated the psychometric properties of the tool in a sample of 263 participants. Exploratory factor analysis showed three factors structure that explained 53\% of the total variable. The internal consistency of the instrument was 0.91 for the whole instrument.

Fasone (2017) addressed study to develop and preliminarily validate a holistic wellness measure intended for application within organizational settings. The measure is referred to as the multidimensional organizational wellness inventory (WOWI) and includes seven wellness subscales (physical, emotional, social, intellectual, spiritual, occupational and environmental). The sample included 120 American Association of Naturopathic physicians (AANP) and American Holistic health Association (AHHA) registered practitioners selected from the organizations' public member databases. The results showed that all four models fit indices showed good model fit in SPSS AMOSS., and all wellness dimension subscales and the total scale yielded composite reliability coefficient that exceeded the 0.70 threshold value.

\subsection{Teacher and wellness}

Teacher is a person trained or recognized and employed to help learning in classroom .So, teachers need certain competences such as health and physical fitness and good fitness behaviors (Ogunjimi, Ikorok, Ekpu, \& Yusuf, 2010,p.17).

Teachers play a central role in facilitating children's cognitive, emotional, and behavioral development for their students .Previous research have demonstrated that high levels of wellness are associated with various domains, including work performance, mental health, physical health, quality relationship with others , and addictive behaviors (Arslan, 2017,p.1-2).

Lau, Lee, \& $\mathrm{Ng}$ (2011,p.152-161) pointed out that the wellness of teacher is most critical in cultivating school connectedness, The role of teachers and their wellness see to be one of the determining factors in promoting school connectedness among students . Teachers have a significant effect on the personal, academic, and career or talent development of students.

Beliard \& Lupinski (2015,p.2) asserted that social, physical , and material resources coping skills can aid teachers in overcoming stressors related to their jobs and attaining achievement outcomes with students , Teachers with high wellness levels influence the learning outcome of students in an encouraging and positive manner .

The present study attempts to examine the structure of wellness for a sample of teachers in Egypt and psychometric properties of wellness inventory.

The study questions addressed are:

1- $\quad$ Is the structure of wellness multidimensional or uni-dimensional?

2- $\quad$ Is wellness inventory has appropriate psychometric properties?

\section{Methodology}

To answer the study questions for this study, it was necessary to select an appropriate inventory of wellness, then the inventory was translated into Arabic language, participants were identified and completed the instrument during 2018 / 2019. Finally, the data collected were combined and analyzed.

\section{Participants}

A total of 417 teachers from Egypt completed the scale of wellness, including males $(\mathrm{N}=260)$ and females $(\mathrm{N}=$ 157). The teachers ranged in age from 29 to 48 with an average age 36.7 and S.D. 1.7.

\section{Instrument}

The measure that used in this study is referred to as the multidimensional organizational wellness inventory (MOWI) (Fasone, 2017), The researchers received acceptance from the author of the inventory, It includes seven wellness subscales (physical, emotional, social, intellectual, spiritual, occupational, and environmental). Each subscale contains 5 items using 5 point Likert response scale, ranging from 1- strongly agree to 5- strongly 
disagree.

\section{Results}

Confirmatory factor analysis (CFA) is used to study the relationships between observed values and latent constructs and comprises the measurement model portion of a structural equation model . CFA additionally, examine the stability of the theorized factor structure, to provide information for measure refinement and to establish the uni-dimensionality of the construct.

Confirmatory factor analysis was conducted in order to further evaluate the items and their structure. The confirmatory factor analysis was done using Analysis of AMOS) software. First, the measurement model for constructs in the structural model was examined. For approximate fit indexes, Goodness of Fit Index (GFI), Adjusted Goodness of Fit Index (AGFI), Normed fit index (NFI), Relative Fit Index (RFI), Incremental Fit Index (IFI), Tucker-Lewis fit index (TFI) and Comparative Fit Index (CFI) of above 0.9 would indicate model fit. More specifically, for Chi-square/df., a value close to 1 is ideal where however values below 5 are considered acceptable. For RMSEA (Root Mean Square Error Approximation), its value should be less than 0.05 although less than 0.1 is suggested to indicate good fit, for NFI, RFI, IFI, TLI and CFI, their values range along a 0-1 continuum, where values above 0.9 typically correspond to good fit.

It is recommended to use multiple and different fit indices where it is suggested to use at least three indexes to assess the model. It is suggested to involve at least one absolute fit index and one incremental fit index in addition to ratio of chi-square to degrees of freedom (normed chi-square) to define the fit of the model. In this research, RMSEA was used as the absolute fit index as it is one of the most informative criteria as to an absolute fit, CFI (Comparative Fit Index) was used as the incremental fit index as it has the ability to adjust for model complexity, in addition to NFI and RFI.

CFA of Wellness Construct: Given that it is a newly developed scale it is suggested to compare competing theoretically plausible models and evaluate which model best fits the data. Confirmatory Factor Analysis was used to confirm the seven-factor solution identified in the exploratory phase. The hypothesized model should fit the data better than alternative model in order confirm the measurement model. To analyze Wellness model fit using CFA, the expected seven-dimensional model was compared to a single factor model ( the item 18 " • I expand my knowledge by listening to the perspectives of people from various cultures, backgrounds, and experiences." was deleted because regression coefficient less 0.3 ). Table 1 shows the detailed of comparison (One-factor model versus 7-factors model):

Table1: Model Fit of Wellness (One- factor model versus seven-factors model)

\begin{tabular}{|c|c|c|c|c|}
\hline & Stats & One factor model & seven factor model & Diff. \\
\hline \multirow{4}{*}{$\begin{array}{c}\text { Model Fit } \\
\text { Summary } \\
\text { (CMIN) }\end{array}$} & Chi-square & 2220.004 & 1743.069 & 476.94 \\
\cline { 2 - 5 } & Probability level & 0.000 & 0.000 & - \\
\cline { 2 - 5 } & CMIN & 2220.004 & 1743.069 & 476.94 \\
\hline \multirow{2}{*}{$\begin{array}{c}\text { Baseline } \\
\text { Comparisons }\end{array}$} & DF & 495 & 455 & 40.00 \\
\cline { 2 - 5 } & CMIN/DF & 4.485 & 3.831 & 0.65 \\
\cline { 2 - 5 } & RFI & 0.658 & 0.732 & 0.07 \\
\cline { 2 - 5 } & IFI & 0.635 & 0.688 & 0.07 \\
\cline { 2 - 5 } & TLI & 0.712 & 0.786 & 0.06 \\
\hline \multirow{2}{*}{ RMSEA } & CFI & 0.710 & 0.784 & 0.07 \\
\cline { 2 - 5 } & RMSEA & .092 & 0.082 & 0.01 \\
\hline
\end{tabular}

Confirmatory analyses for both the models were performed using AMOS. Comparing indices in table 1, It is clear that the data better fits the seven-factor model. A chi-square difference test, with $\chi 2$ diff $=476.94$ and df. diff $=40.00$, reveals a significant difference where the 7 - factors model fits the data better. Values of this ratio for the one-factor model and 7-factors model are found to be 4.485 and 3.831, respectively. The RFI values for 1 -factor model and 7-factors model are 0.635 and 0.688 , and they change in favor of the 7-factors model. Values of IFI (0.712 and 0.786$)$ as well as TLI (0.691and 0.749$)$ for 1 -factor and 7-factors models are found to be in favor of the 7- factors model. However, 7 -factors model fit indices did not entirely meet the suggested limits, thus modification indices were examined in order to improve the model fit.

The following table shows the standard regression and regression weights: 
Table 2 : Std. Regression and Regression Weights:

\begin{tabular}{|c|c|c|c|c|c|c|c|}
\hline \multicolumn{3}{|r|}{ paths } & std. Estimate & Estimate & S.E. & C.R. & Sig. \\
\hline 5 & $<---$ & Physical wellness & .585 & 1.081 & .114 & 9.500 & 0.01 \\
\hline 4 & $<---$ & Physical wellness & .479 & .876 & .102 & 8.568 & 0.01 \\
\hline 3 & $<---$ & Physical wellness & .407 & .766 & .102 & 7.525 & 0.01 \\
\hline 2 & $<---$ & Physical wellness & .566 & .960 & .092 & 10.444 & 0.01 \\
\hline 1 & $<---$ & Physical wellness & .549 & 1.000 & & & \\
\hline 10 & $<---$ & Social wellness & .510 & .907 & .133 & 6.837 & 0.01 \\
\hline 9 & $<---$ & Social wellness & .538 & 1.175 & .171 & 6.854 & 0.01 \\
\hline 8 & $<---$ & Social wellness & .586 & 1.605 & .209 & 7.692 & 0.01 \\
\hline 7 & $<---$ & Social wellness & .651 & 1.427 & .164 & 8.679 & 0.01 \\
\hline 6 & $<---$ & Social wellness & .438 & 1.000 & & & \\
\hline 20 & $<---$ & Intellectual wellness & .761 & 1.184 & .097 & 12.242 & 0.01 \\
\hline 19 & $<---$ & Intellectual wellness & .538 & .938 & .098 & 9.567 & 0.01 \\
\hline 17 & $<---$ & Intellectual wellness & .625 & .971 & .086 & 11.341 & 0.01 \\
\hline 16 & $<---$ & Intellectual wellness & .578 & 1.000 & & & \\
\hline 25 & $<---$ & Spiritual wellness & .652 & 1.517 & .187 & 8.125 & 0.01 \\
\hline 24 & $<---$ & Spiritual wellness & .762 & 1.831 & .214 & 8.573 & 0.01 \\
\hline 23 & $<---$ & Spiritual wellness & .494 & 1.128 & .143 & 7.879 & 0.01 \\
\hline 22 & $<---$ & Spiritual wellness & .221 & .629 & .152 & 4.146 & 0.01 \\
\hline 21 & $<---$ & Spiritual wellness & .408 & 1.000 & & & \\
\hline 30 & $<---$ & Occupational wellness & .725 & 1.223 & .101 & 12.074 & 0.01 \\
\hline 29 & $<---$ & Occupational wellness & .790 & 1.401 & .109 & 12.828 & 0.01 \\
\hline 27 & $<---$ & Occupational wellness & .674 & 1.177 & .103 & 11.430 & 0.01 \\
\hline 26 & $<---$ & Occupational wellness & .625 & 1.000 & & & \\
\hline 11 & $<---$ & Occupational wellness & .225 & 1.000 & & & \\
\hline 12 & $<---$ & Emotional wellness & .682 & 2.396 & .577 & 4.154 & 0.01 \\
\hline 13 & $<---$ & Emotional wellness & .636 & 2.556 & .620 & 4.122 & 0.01 \\
\hline 15 & $<---$ & Emotional wellness & .747 & 2.999 & .716 & 4.189 & 0.01 \\
\hline 14 & $<---$ & Emotional wellness & .250 & 1.135 & .298 & 3.802 & 0.01 \\
\hline 31 & $<---$ & Environmental wellness & .507 & 1.000 & & & \\
\hline 32 & $<---$ & Environmental wellness & .671 & 1.379 & .151 & 9.117 & 0.01 \\
\hline 33 & $<---$ & Environmental wellness & .739 & 1.599 & .168 & 9.539 & 0.01 \\
\hline 34 & $<---$ & Environmental wellness & .595 & 1.362 & .171 & 7.985 & 0.01 \\
\hline 35 & $<--$ & Environmental wellness & .650 & 1.136 & .127 & 8.967 & 0.01 \\
\hline
\end{tabular}

From the above table it is clear that the paths are significant for all factors.

The CFA model should be purified through dropping items with low factor loadings, where considered loadings above .6 to be "high" and loadings below .4 "low". All of the path coefficients were statistically significant, and all items loaded well above 0.4 , where standardized regression weight (standardized loading factor) estimates signify that the indicator variables are significant and representative of their latent variable .

Internal consistency:

We evaluated internal consistency with the correlation of dimension with the total scores of the scale(Table3), also Correlation with total score was assumed. 
Table 3: Correlation with total score

\begin{tabular}{|c|c|}
\hline Factors & Correlation with total score \\
\hline Wellness & - \\
\hline Physical wellness & $.83^{* *}$ \\
\hline Social wellness & $.81^{* *}$ \\
\hline Emotional wellness & $.75^{* *}$ \\
\hline Intellectual wellness & $.85^{* *}$ \\
\hline Spiritual wellness & $.82^{* *}$ \\
\hline Occupational wellness & $.84^{* *}$ \\
\hline Environmental wellness & $.82^{* *}$ \\
\hline
\end{tabular}

** sig. at 0.01 level

From the above table it can be seen that Correlation with total score is significant at 0.01 level.

Constructs Reliability:

After conducting confirmatory factor analysis for all constructs, reliability of construct was estimated one more time by calculating Cronbach's alpha value. The Cronbach's alpha value for scale ranged from 0.56 to 0.92 (Table4),

Table 4: Reliability of Wellness

\begin{tabular}{|c|c|}
\hline Factors & Cronbach's Alpha \\
\hline Wellness & 0.92 \\
\hline Physical wellness & 0.66 \\
\hline Social wellness & 0.67 \\
\hline Emotional wellness & 0.66 \\
\hline Intellectual wellness & 0.59 \\
\hline Spiritual wellness & 0.69 \\
\hline Occupational wellness & 0.56 \\
\hline Environmental wellness & 0.75 \\
\hline
\end{tabular}

From the above table it can be seen that Cronbach's Alpha is appropriate.

\section{Conclusion}

The results indicates that The structure of wellness is multidimensional which includes physical, emotional, social, intellectual, spiritual, occupational, and environmental. And the inventory has appropriate psychometric properties.

\section{References}

Adams, T., Bezner, J., Drabbs , M. , Zambarano , R. , \& Steinhardt , M. (2000) . Conceptualization and measurement of the spiritual and psychological dimensions of wellness in college population. Journal of American College Health, 48 (4), 165-173.

Al Hadid, L. , Becker, C. , Mansour, A. , Al- Shubi, J. , Tharwat, H. , \& Glascoff, N. (2013). Salutogenic wellness promotion scale: Validation of the Arabic version. American Journal of health Education, 44 (4), 299-234.

Arslan, G. (2017). Understanding the association between positive psychological functioning at work and cognitive well being in teacher. Journal of Positive Psychology and wellbeing, 1-15.

Bates , J. , Cooper, D. , \& Wachs, P. (2001). Assessing wellness in college students: A validation of the salubrious lifestyle scale of the student development task and lifestyle assessment. Journal of College Student Development, 42 (3), 193-203.

Beauchemin, J. (2015). Examining the effectiveness of a short-term solution - focused wellness group intervention on perceived stress and wellness among college students. Dissertation presented in partial fulfillment of the requirements for the degree doctor of philosophy in the graduate school of the Ohio State University.

Becker, C., Moore, J. , Whetstone, L ., Glascoff, M., Chaney, E., Felts, M., \& Anderson, L. (2009). Validity evidence for the salutogenic wellness promotion scale (SWPS). American Journal of Health Behavior, 33 (4), 455-465.

Becker, C., Whetstone, L. Glascoff, M., \& Moore, J. (2008). Evaluation of the reliability and validity an adult version of the salutogenic wellness promotion scale (SWPS). American Journal of Health Education, 39 (6), 322-328.

Beliard, J., \& Lupinski, K. ( 2015). A comparison of program methods to increase elementary teachers' wellness knowledge; Web based and face - to - face. Journal of Teaching, Learning, and scholarship,2 ( 2 ), 1-30. 
Day-Vines, N. , \& Holocomb-Mccoy, C. (2007). Wellness among African American counselors. Journal of Humanistic Counseling, Education and Development, 46, 82-97.

Fasone , K. (2017). Development and preliminary validation of a multi-dimensional wellness inventory: Designing a tool for application in organizational settings. A Dissertation submitted to the faculty of the Chicago school of professional psychology, In partial fulfillment of the requirements for the Degree of Philosophy in psychology.

Fridlund, B. , Martensson, J., Baigi, A. , \& Brostorm, A. (2015). Establishing the psychometric properties of the comprehensive ethos towards wellness questionnaire in a Norwegian population. Journal of Holistic Nursing, 33 (4), 366-373.

Gradidge, D. , \& De Jager, A. (2011). Psychometric properties of the wellness questionnaire for higher education. South African Journal of Psychology, 41 (4), 517-527.

Harari, M. ,Waehler, C. , \& Rogers, J. (2005). An empirical investigation of a theoretically based measure of a perceived wellness. Journal of Counseling Psychology, 52 (1), 93-103.

Hattie, J. , Myers , J. , \& Sweeney , T. (2004). A factors structure of wellness: Theory, assessment, analysis , and practice. Journal of Counseling \& Development, 82, 354-364.

Hurtado - Pardos, B. ,Casas , I. ,Lluch- Canut, T. , Moreno - Arroyo, C. , Nebot-Bergua, C. , \& Roldan - Merino, J . (2016). Psychometric evaluation of a new instrument in Spanish to measure the wellness of university nursing faculty. Archives of Environmental \& Occupational Health, https://doi.org/10.1080/19338244.2016.1246411.

Jankowski- Koch, R. (2014). Wellness education: Linking learning and success (WELLS): A program for first year clinical psychology doctoral students. A Dissertation submitted to the faculty of the Chicago school of professional psychology, In partial fulfillment of the requirements for the Degree of Doctor of psychology.

Lau, P., Lee, O., \& Ng, H. (2011). Teacher wellness: An important issue in fostering school connectedness and high skills development among student. Asian Journal of Counselling, 18 ( 1 ) ,149 - 169 .

Lowe, R. (2015). The relationship between personality, self-care, stress, and perceived wellness in psychology doctoral students. A Dissertation submitted of the graduate school of Tennessee State University, In partial fulfillment of the requirements for the Degree of Doctor of philosophy.

Myers, J., Luecht, R., \& Sweeney, T. (2004). The factor structure of wellness: Reexamining theoretical and empirical models underlying the wellness evaluation of lifestyle (WEL) and the five - factor wel. Measurement and Evaluation In Counseling and Development, 36 ( 6 ). 194-206.

Ogunjimi , L. , Ikorok, M. , Ekpu, F. , \& Yusuf, O. (2010).Wellness attitudes of secondary school teachers in cross River state, Nigeria. International NGO Journal, 5 (1), 12 - 20 .

Palombi, B. (1992). Psychometric properties of wellness instruments. Journal of Counseling \& Development, 71 (2), 221-225.

Rachele, J., Cuddihy, T., Washington, T., \& Mc Phail, S. (2014). Reliability of a wellness inventory of use among adolescent females aged 12-14 years. Women's Health, 14 (87), 1-6.

Rachele, J., Washington, T., Cuddihy, T., Barwais, F. , \& Mc Phail, S. (2013). Valid and reliable assessment of wellness among adolescents: Do you know what you're re measuring? International Journal of Wellbeing, 3 (2) $162-172$.

Ragheb, M. (1993). Leisure and perceived wellness: A field investigation. Leisure Sciences, 15, 13 - 24.

Roig , J. (2017). The relationship between psychological capital and holistic wellness among faculty. $A$ Dissertation presented in partial fulfillment of the requirement for the Degree Doctor of philosophy, Capella University.

Roscoe, L. (2009). Wellness: A review of theory and measurement for counselors. Journal of Counseling of Development, 87, 216-226.

Rucker, M (2016). Effective workplace wellness strategies: How small and mid-size business are effectively using wellness strategies to improve employee well-being. Dissertation presented to the faculty of the California school of professional psychology, Alliant International University, San Francisco, in partial fulfillment of the requirements for the Degree of Doctor of philosophy.

Schueller, S. (2009). Promoting wellness: Integrating community and positive psychology. Journal of Community Psychology, 37 (7), 922-937.

Vafaeenia, H. (2014). Holistic wellness for coping with anxiety and stress in college students. In partial fulfillment of the requirement for the Degree Master of arts Saint Mary's college of California.

Wolf, C., Thompson, I., \& Smith - Adcock, S. (2012). Wellness in counselor preparation: Promoting individual well- being. The Journal of Individual Psychology, 68 (2), 164-181.

Young, T., Turnage - Butterbaugh, I., Degges-White, S., \& Mossing, S. (2015). Wellness among undergraduate students on academic probation: Implication for college counselors. Journal of College Counseling, 18, $222-232$ 
First A. Author: Mokhtar Ahmad Al-Kayal

- Professor (Educational Psychology) Ain Shams University, Cairo, EGYPT, 26/9/2009.

- Head of Educational Psychology Department Faculty of Education, Ain Shams University (2013- 2019).

- Ph.D., (Educational Psychology) Ain Shams University, Cairo, EGYPT, Thesis Title "Physiological Brain Activity Associated With the Ability to Recall: A psycho- physiological Study"

- M.A., (Educational Psychology) Ain Shams University, Cairo, EGYPT, Thesis Title "The Relationship between Social Responsibility, Self-Concept and Locus of Control among College Student.

-Special Diploma (Education \& Psychology), Ain Shams University, Cairo, EGYPT 1983.

- B.A.in Science \& Education (Biology) Ain Shams University, Cairo, EGYPT.

-Director of Psychological Counseling Center. Ain Shams University, Cairo, EGYPT (5/10/2010 - 5/ 10 /2012).

- Member of Arab association for Psychological Sciences.

- Member of Arab Association for Educational and Psychological Assessment.

- Member of Management council of Egyptian Association for Psychological studies.

- Member of the Egyptian Association for Psychological studies.

- Member of the Egyptian Psychological Association.

- Member of Association of Modern Education.

- Member of, Higher Committee for promotion (Level of professors, And Associate professors of Educational Psychology).

- Member of Higher Council of Culture, Ministry of Culture (Committee of Psychology).

- Member of Management Council of Faculty of Education, Ain shams University.

- Member of Management Council of Psychological Counseling Center, Faculty of Education, Ain shams University.

- Member of Undergraduate Students Affairs, Faculty of Education, Ain shams University.

- Member of Academic Counseling Committee, College of Humanities and Social Sciences, UAEU.

- Member of Postgraduate Students Affairs, Faculty of Education, Ain Shams University.

- Editor in chief of Psychological Counseling Journal, Faculty of Education, Ain shams University (Psychological Counseling Center).

- Editorial Board Member of many Local and Regional Journals of Psychology, as Examples, Journal of Psychological Studies, Issued by Faculty of Education, Ain Shams University,-Journal of Psychological Studies, issued by The Egyptian Association for Psychological Studies,-Arab Journal of Measurement, issued by Arab Association for Educational and Psychological Assessment, Journal of Psychological Measurement, Ain shams University (Psychological Measurement Center), and etc.

- Areas of Research Interest: Cognitive Psychology - Psychology of Learning - Physiological PsychologyEducational and Psychological Measurement.

Emails: Mokhtar_elkial@edu.asu.edu.eg

mokhtarelkayal@yahoo.com

\section{Second A.Author: Mohammad Ismail Sayed Hemeda}

- Place of birth: Al - Maqatfeya Village - Al Ayat Center - Giza Governorate, Date of Birth: 1/9/1975.

- Assistant Professor of Educational Psychology - Faculty of Education - Ain Shams University, 2015.

- Member of the Board of the Department of Educational Psychology, Faculty of Education, Ain Shams

University.

- Member and Coordinator of the Quality Committee, Department of Educational Psychology - Faculty of Education, Ain Shams University.

- Member of the Environment and Society Committee, Faculty of Education, Ain Shams University.

- Member of the Egyptian Association for Psychological Studies.

- Bachelor of Arts and Education (Department of English) - (very good grade, the first), 1998.

- Professional diploma, specialization of school psychology (very good grade), 2001.

- Special Diploma in Education, Educational Psychology (very good grade), 2002.

- Master of Education (Educational Psychology) (excellence with the recommendation to exchange the message with the Egyptian and Arab universities and specialized research centers). Thesis Title: The impact of different characteristics of tasks and activities of the learner on the objectives of achievement goals among students in the preparatory stage, Faculty of Education - Ain Shams University, 2006.

- Ph.D. in Education (Educational Psychology) with a recommendation to exchange the message with the Egyptian and Arab universities and specialized research centers. Thesis title: The effectiveness of a program to develop reading comprehension in English for high school students, 2010, Faculty of Education - Ain Shams University. 
Third A. Author: Mohammad Ali Haeba

- Born in Cairo, 1977.

- Member of the Egyptian Association for Psychological Studies, 2015.

- Professional Diploma, 2001.

- Special Diploma, 2002.

- Master in Educational Psychology, 2007.

- Ph.D. Educational Psychology, 2011.

- Assistant Professor of Educational Psychology, Faculty of Education, Ain Shams University.

Fourth A. Author: Walid Hassan Ashour El Khateeb

- Born in Giza, 1981.

- Member of the Egyptian Association for Psychological Studies 2005- Professional Diploma, 2003.

- Special Diploma, 2005.

- Master in Educational Psychology, 2009.

- Ph.D. Educational Psychology, 2013.

- Lecturer of Educational Psychology, Faculty of Education, Ain Shams University, Jouf University. 